\title{
Acute primary HIV infection
}

\author{
Michael L. Rekart MD, Josephine Maclntosh PhD
}

\begin{abstract}
Although most patients with acute HIV infection are symptomatic, the diagnosis is often missed
\end{abstract}

In a descriptive cohort study, 41 of 46 people with acute HIV infection sought medical attention for related symptoms. ${ }^{1}$ Seventy per cent reported experiencing such symptoms as fever, fatigue, sore throat and weight loss for a median of 14 days. Only $25 \%$ received a correct diagnosis.

\section{Routine HIV testing will miss most acute infections}

The usual HIV screening tests third- and fourth-generation enzyme immunoassays - begin to identify infection within 22 days after exposure. ${ }^{5}$ However, patients are often advised to wait 12 weeks after risky behaviour before testing. ${ }^{5}$ This will result in missed opportunities to diagnose acute HIV infection.

\section{HIV infection can often be detected within 22 days after exposure}

Third-generation enzyme immunoassays start to detect anti-HIV antibodies within 20-22 days after exposure; fourthgeneration enzyme immunoassays, which test for p24 antigen and anti-HIV antibodies, can yield positive results within 16-18 days. ${ }^{5}$ RNA nucleic acid amplification testing starts to detect HIV infection within 7-14 days. At $\$ 75$ per test, these RNA tests are too costly for routine use and are typically reserved to detect pre-seroconversion infection in at-risk prenatal women and to rule out neonatal infection.

\section{Risk of transmission may be greatest within three months after infection}

Well-designed studies have shown very high HIV viral loads in blood, semen and vaginal secretions during the first two to three months after infection (Figure 1). ${ }^{2}$ Research suggests that up to $49 \%$ of transmission events could be ascribed to recently infected index subjects. ${ }^{4}$

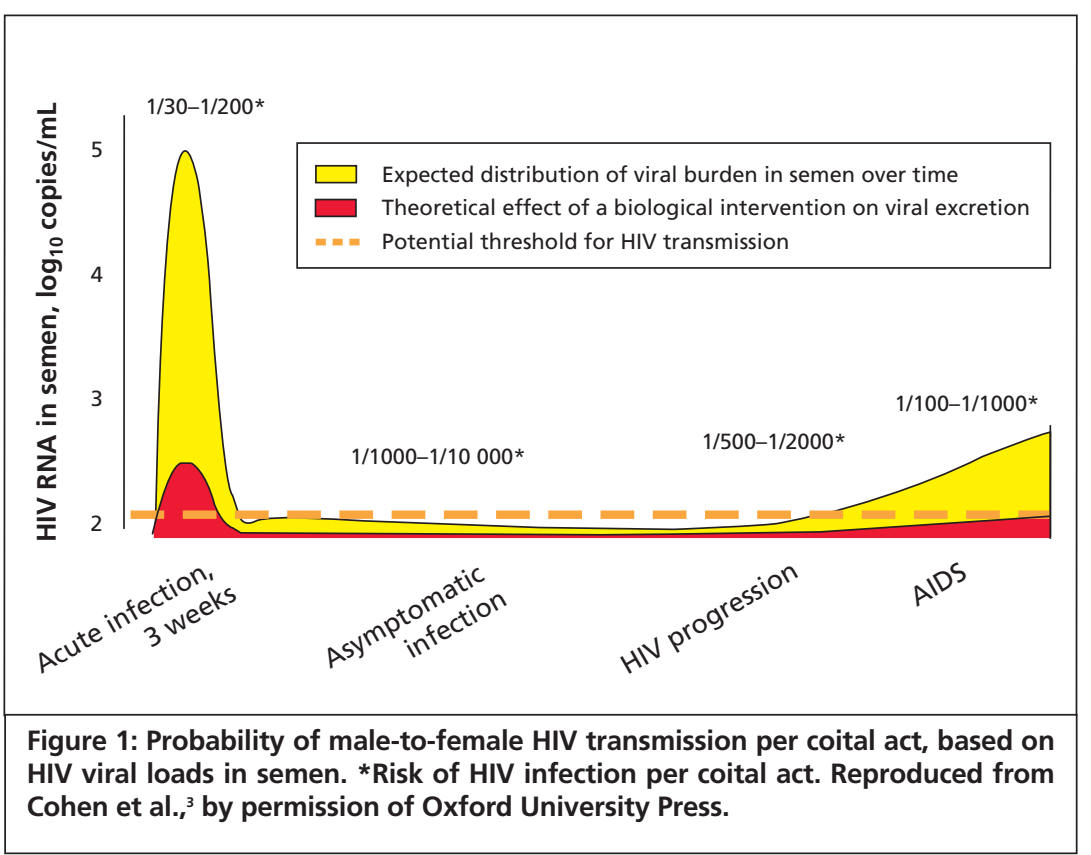

Most patients who know they have acute HIV infection will change their behaviour

In one study, $76 \%$ of 98 high-risk homosexual men with acute HIV infection eliminated the risk of forward HIV transmission for 12 weeks after diagnosis. ${ }^{6}$ Early diagnosis also allows for timely initiation of treatment.
For references, see Appendix 1 (available at www.cmaj.ca/lookup/suppl/doi:10.1503/cmaj .101605/-/DC1).

\section{Competing interests: None declared.}

This article has been peer reviewed.

Affiliations: From the BC Centre for Disease Control (Rekart), Vancouver, BC; the University of British Columbia (Rekart, MacIntosh), Vancouver, BC; and the University of Victoria (MacIntosh), Victoria, BC

Correspondence to: Dr. Michael L. Rekart, michael.rekart@bccdc.ca

CMAJ 2011. DOI:10.1503/cmaj.101605 